\title{
Suprarenal Vein
}

National Cancer Institute

\section{Source}

National Cancer Institute. Suprarenal Vein. NCI Thesaurus. Code C53129.

A vein that returns blood to the heart from the adrenal gland. The right adrenal vein empties directly into the inferior vena cava and the left adrenal vein empties into the left renal vein. 